\title{
Kinetics and Mechanism of the Addition of Benzylamines to Benzylidene Meldrum's Acids in Acetonitrile
}

\author{
Hyuck Keun Oh, ${ }^{\dagger}$ Tae Soo Kim, ${ }^{\dagger}$ Hai Whang Lee, and Dkchoon Lee ${ }^{\circ}$ \\ ${ }^{\dagger}$ Department of Chemistry, Chonbuk Wational Lniversity, Jeonin 560-756, Korea \\ Department of Chemistry, Inha Lniversity, Inchon 402-751, Norea \\ Received November $14_{1} 2002$
}

\begin{abstract}
Nucleophilic addition reactions of benzylamines $\left(\mathrm{XC}_{6} \mathrm{H}_{4} \mathrm{CH}_{2} \mathrm{NH}_{2}\right)$ to benzylidene Meldrum's acids (BMA; $\left.\mathrm{YC}_{6} \mathrm{H}_{4} \mathrm{CH}=\mathrm{C}(\mathrm{COO})_{2} \mathrm{C}\left(\mathrm{CH}_{3}\right)_{2}\right)$ have been investigated in acetonitrile at $20.0^{\circ} \mathrm{C}$. The rates of addition are greatly enlhanced due to the abnonnally high acidity of Meldrum's acid. The magnitudes of the Hanmett ( $\rho_{\mathrm{X}}$ and $\left.\rho_{1}\right)$ and Brönsted $\left(\beta_{\mathrm{X}}\right)$ coefficients are rather small suggesting an early transition state. The sign and magnitude of the cross-interaction constant. $\rho_{\mathrm{XY}}(=-0.33)$. and kinetic isotope effects $\left(k_{\mathrm{H}} / k_{\mathrm{D}} \cong 1.5-1.7\right)$ involving deuterated benzylamine micleoplilies $\left(\mathrm{XC}_{6} \mathrm{H}_{4} \mathrm{CH}_{2} \mathrm{ND}_{2}\right)$ are indicative of hydrogen-bonded cyclic transition state. The activation parameters. $\Delta H^{F} \cong 4 \mathrm{kcal} \mathrm{mol}^{-1}$ and $\Delta s^{+} \cong-37$ e.u.. are also in line with the proposed mechanism.
\end{abstract}

Key Words : Benzylidene Meldrum's acid. Nucleophilic addition reaction, Cross-interaction constant

\section{Introduction}

The nucleophilic attack to carbon-carbon double bonds has been the subject of numerous investigations. ${ }^{1}$ Nucleophilic vinylic substitution reactions activated by electronwithdrawing groups $\left(Z . Z^{\prime}\right)$ are known to proceed by the twostep mechanism. eq. (l). where $L G=$ leaving group and $\mathrm{Nu}$ $=$ nuclephilie. ${ }^{l}$ The primary addition step, $k_{\mathrm{a}}$, leads to an association complex or intermediate which for amine base is a zwitterion, $\mathrm{T}^{ \pm}$.

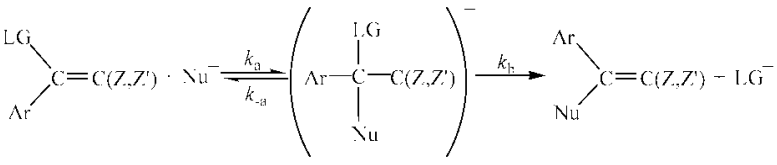

In the simple nucleophilic vinylic additions, however, when the anines are primary or secondary. intramolecular proton transfer may inumediately follow or even simultaneously upon formation of $\mathrm{T}^{ \pm 1}{ }^{1 \mathrm{2} .3}$ eq. (2). Previous works

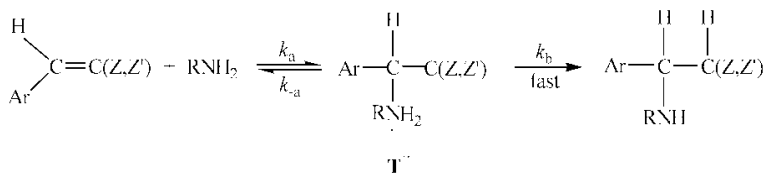

have shown that in aqueous solution ${ }^{\text {lbs }}$ the mechanism of nucleoplilic addition to activated olefines is complex involving group separated products formation following the rate-limiting addition step. $k_{\mathrm{a}}$. with imbalanced transition states in which the development of resonance to the activating groups ( $\left.Z . Z^{\prime}\right)$ lags behind charge transfer or N-C bond formation. In contrast. the amine addition in acetonitrile 3 was found to be a relatively simple one, i.e. one step addition.

In this work we report kinetic study of the nucleophilic

addition of benzylamines to benzylidene Meldrum's acids (BMAs) in acetonitrile at $20.0^{\circ} \mathrm{C}$, eq. (3). Meldrum's acid 1 .

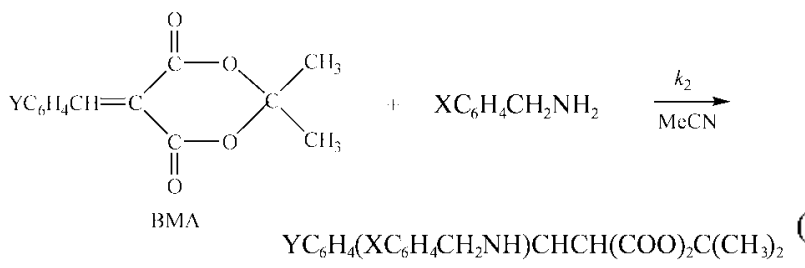

has attracted considerable attention due to its high acidity, ${ }^{4}$ higher $\left(\mathrm{p} K_{\mathrm{a}}=7.3\right)$ than its acyclic analogues such as dimethyl malonate $\left(2 ; \mathrm{p} K_{4}=15.9\right)$ or even the diketone analogue (3; $\left.\mathrm{p} K_{\mathrm{a}}=11.2\right)^{4 \mathrm{t}}$ The nucleophilic addition reactions to BMA in aqueous solution have been investigated extensively by Bemasconi et $a^{5}$ They reported some unusual kinetic behaviors in the addition reaction of BMA.<smiles>CC1(C)OC(=O)CC(=O)O1</smiles>

The primary purpose of this study is to elucidate the mechanism of primary amine addition to BMA in acetonitrile. Since the Meldrum's acid in BMA is known to have unusually strong power of stabilizing the anion formed in the primary attack, we are interested especially in the rates of addition ( $k_{2}$ step in eq. (3)) and in the degree of bond formation in the TS by detemining the Hammett $\left(\rho_{\mathrm{X}}\right)$ and Brönsted coefficients $\left(\beta_{\mathrm{X}}\right)$. and cross-interaction constant, ${ }^{6}$ $\rho \mathrm{YY}$ in eqs. (4), where $\mathrm{X}$ and $\mathrm{Y}$ are the substituents in the nucleophile (benzy lamine) and substrate (BMA), respectively.

$$
\log \left(k_{\mathrm{XY}} / k_{\mathrm{HH}}\right)=\rho_{\mathrm{Y}} \sigma_{\mathrm{Y}}+\rho_{\mathrm{Y}} \sigma_{\mathrm{Y}}+\rho_{\mathrm{Y} Y} \sigma_{\mathrm{Y}} \sigma_{\mathrm{Y}}
$$




$$
\rho_{\mathrm{XY}}-\partial \rho_{\mathrm{Y}} / \partial \sigma_{\mathrm{X}}-\partial \rho_{\mathrm{X}} / \partial \sigma_{\mathrm{Y}}
$$

In aqueous solution, the magnitude of $\beta_{\mathrm{X}}\left(\beta_{\text {nuc }}\right)$ determined with piperidine and morpholine pair has been shown to be exceptionally small $\left(\beta_{\mathrm{X}}=0.07\right)^{\mathrm{sit}}$ but that with primary amines is somewhat larger with $\beta_{X}=0.22 .^{5 \mathrm{~s}}$ It is of interest to find out whether such unusual behaviors in aqueous solution persist in acetonitrile or not.

\section{Results and Discussion}

A clean second-order kinetics according to eqs. (5) and (6) was obtained throughout this work. where $k_{2}$ is the secondorder rate constant for the benzylamine (BnA) addition to

$$
\begin{gathered}
\text { Rate }^{-} k_{\text {ollosid }}[\mathrm{BMA}] \\
k_{\text {obsud }}=k_{2}[\mathrm{BnA}]
\end{gathered}
$$

the benzylidene Meldrum's acid (BMA) under pseudo-firstorder condition $\left(k_{013 . d}\right)$ with large excess of amine nucleophiles. Plots of $k_{\text {cbss }}$ against [BnA] were linear for $c u$. 10fold increase in [BnA]. The $k_{2}$ values determined from the slopes of these plots are summarized in Table 1. The rates are compared with those involving other activating groups, $Z, Z^{\prime}$, in Table 2 . The rates in acetonitrile are much slower than those $\left(\log k_{0}\right)$ in aqueous solution. Excepting for the amine addition to $\mathrm{BM} \Lambda$, the reaclivity in aqueous solution increases with the (polar) electron-withdrawing power $(\Sigma \sigma)^{7}$ of the activating groups whereas that in acetonitrile depends on the through conjugative electron-withdrawing strength $\left(\Sigma \sigma^{-}\right)^{7}$ of the activating groups. We note that the reactivity of $\mathrm{BMA}$ is exceptionally large in aqueous solution as well as in acetonitrile. The $\Sigma \sigma-0.75$ should place the reactivity of BMA to the lowest place but the $\log k_{0}$ value is the second after that of BMN for which $\Sigma \sigma^{-}$1.32. Again the $\Sigma \sigma^{-}-$ 1.38 should give the reactivity of BMA in acetonitrile less than that of BID $\left(\Sigma \sigma^{-}-2.08\right)$ but the reactivity of BMA in acetonitrile is the largest. The enhanced reactivity of the amine addition to $\mathrm{BM} \wedge$ no doubt reflects the unusually strong acidity of the Meldrum's acid due to strong stabilizing power of the Meldrum's acid anion, ${ }^{2,4.5}$ in which the anionic charge is delocalized, $1 \mathbf{A}$.

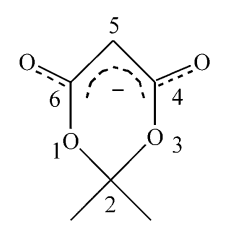

$1 \mathrm{~A}$

The anomalously high acidity of $\mathbf{1}$ has been a subject of exiensive theoretical as well as experimental investigations.

\begin{tabular}{|c|c|c|c|c|c|}
\hline \multirow{2}{*}{$\mathrm{X}$} & \multicolumn{4}{|c|}{ Y } & \multirow{2}{*}{$\rho_{\gamma}^{h}$} \\
\hline & $p$-OML & $p-\mathrm{Mc}$ & $\mathrm{H}$ & $p-\mathrm{CI}$ & \\
\hline \multirow[t]{3}{*}{$p-O M c$} & 74.4 & 86.4 & 101 & 132 & $0.49 \pm 0.02$ \\
\hline & $48.7^{\circ}$ & & & 85.8 & \\
\hline & $32.4^{d t}$ & & & 56.3 & \\
\hline$p-M_{L}$ & 71.9 & 80.3 & 93.5 & 117 & $0.42 \pm 0.01$ \\
\hline $\mathrm{H}$ & 67.2 & 73.9 & 86.6 & 106 & $0.40 \pm 0.01$ \\
\hline \multirow[t]{3}{*}{$p-\mathrm{CI}$} & 62.6 & 68.0 & 76.6 & 91.0 & $0.32 \pm 0.0 \mathrm{I}$ \\
\hline & 42.1 & & & 60.3 & \\
\hline & 28.4 & & & 40.6 & \\
\hline$m-\mathrm{C}]$ & 59.3 & 62.1 & 70.4 & 78.9 & $0.26 \pm 0.02$ \\
\hline$\rho x^{\circ}$ & $-0.15 \pm 0.01$ & $-0.21 \pm 0.01$ & $-0.24 \pm 0.01$ & $-0.33 \pm 0.02$ & $\rho x r^{2}$ \\
\hline$\beta_{X^{\prime}}$ & $0.15 \pm 0.01$ & $0.21 \pm 0.01$ & $0.23 \pm 0.05$ & $0.32 \pm 0.02$ & $=-0.33 \pm 0.03$ \\
\hline
\end{tabular}

Table 1. The second-order rate constants. $k_{2}\left(\mathrm{M}^{-1} \mathrm{~s}^{-1}\right)$. and selectivity parameters for the addition of X-benzylamines to Y-benzylidene Mcldrum's acids in acetonitrilc at $20.0^{\circ} \mathrm{C}$

"The $\sigma$ values were taken from rel. 7. The $p K_{\text {: }}$ values were taken lrom ref. 8 . The $p K_{1}-9.67$ was used for $\mathrm{X}^{-} p$-CII $\mathrm{O} O$ (rel. 9). "Correlation coefficients were better than 0.996 in all cases. 'A1 $10.0^{\circ} \mathrm{C}$. "At $0.0^{\circ} \mathrm{C}$. "Correlation coeflicients were betler than 0.994 in all cases. 'Contation coeflicients were

\begin{tabular}{|c|c|c|c|c|c|c|c|c|}
\hline Entry & Z.Z' & $k_{2}^{\prime \prime} / \mathrm{M}^{\prime} \mathrm{s}^{\prime}$ & $\log k^{h}{ }^{h}$ & $\rho_{\times^{\prime}}$ & $\rho_{r}{ }^{\prime}$ & $\rho_{\mathrm{XY}^{c^{\prime f}}}$ & $\Sigma \sigma^{\prime \prime}$ & $\Sigma \sigma f$ \\
\hline $1(\mathrm{BMA})^{2}$ & $(\mathrm{COOO})_{2} \mathrm{CMe}_{2}$ & $86.6\left(20^{\circ} \mathrm{C}\right)$ & $\approx 4.10$ & -0.24 & 0.40 & -0.33 & 0.75 & 1.38 \\
\hline $2(\mathrm{BM} N)^{h}$ & CA:CN & $1.48^{\prime}$ & 4.94 & -1.62 & -0.55 & -0.31 & 1.32 & 2.00 \\
\hline $3(\mathrm{BI} \Gamma)^{I}$ & $\left(\mathrm{CO}_{2} \mathrm{C}_{6} \mathrm{H}_{4}\right.$ & 1.48 & - & -1.10 & 0.41 & -0.33 & 0.83 & 2.08 \\
\hline $4(\mathrm{NS})^{j}$ & $\mathrm{NO}_{3} .11$ & $2.63 \times 10^{-2}$ & 2.55 & -1.22 & 1.73 & -0.40 & 0.78 & 1.27 \\
\hline $5(\mathrm{NSSI}))^{k}$ & $\mathrm{NO}_{2} \cdot \mathrm{C}_{4} \mathrm{H}_{5}$ & $2.69 \times 10^{-2}$ & 1.42 & -0.82 & 1.27 & -0.52 & 0.77 & $1.27^{m+1}$ \\
\hline $6(\mathrm{CNS})^{h}$ & $\mathrm{C} \mathrm{N}, p-\mathrm{NO}_{2} \mathrm{C}_{6} \mathrm{I}_{4}$ & $1.26 \times 10^{-i}\left(30^{\circ} \mathrm{C}\right)$ & $\approx 3.35$ & -1.15 & 1.10 & -0.67 & 0.92 & $1.00^{\prime \prime}$ \\
\hline
\end{tabular}
betler than 0.993 in all cases. "Cortelation coellicient was 0.998 .

Table 2. Comparisons of reactivity parameter for the addition reaction. $\mathrm{YC}_{6} \mathrm{I}_{+} \mathrm{CII}=\mathrm{C}_{6} \gamma^{\prime}+\mathrm{XC}_{6} \mathrm{IL}_{4} \mathrm{CH}_{2} \mathrm{NII}_{2}$ in acetonitrile

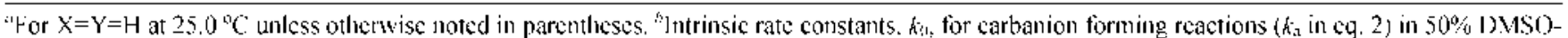

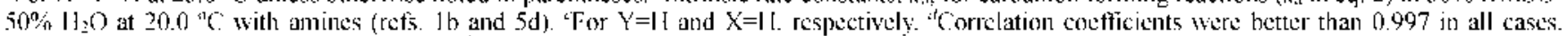
"Normal H lammett substituent constant $\left(\sigma_{p}\right)$. 'Exalted substiluent constant $\left(\sigma_{p}{ }^{-}\right)$for direct conjugation will anionic functional center (rel. 7 ). "This work.

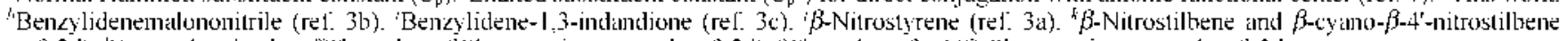

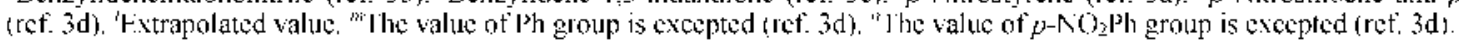


Arnett et $a f^{\text {th }}$ measured acidity constants of esters and lactones that are relevant to the Meldnum's acid and attributed the strong acidity of 1 to restricted rotation which faces the ester groups to adopt unfavorable anti conformation in Meldnum's acid. Wiberg $e t a f^{\text {te }}$ studied the acidity difference between syn and anti rotamers of methyl acetate theoretical$\mathrm{ly}$ at the MP $3 / 6-31 \mathrm{G}^{* *} / \mathrm{HF} / 6-31 \mathrm{G}^{*}$ level ${ }^{16}$ and concluded that the change in charge distribution that accompanies the more facile loss of proton from the anti rotamer (by $4.7 \mathrm{kcal}$ $\mathrm{mol}^{-1}$ ) leads to the unusual acidity of Meldnum's acid having a bis (anti) conformation. Wang and Houk ${ }^{4 b}$ also reported ab initio calculations on the acidity of methyl acetate in syn and anti conformations at the $\mathrm{HF} / 6-31+\mathrm{G}^{*} / / \mathrm{HF} / 3-21 \mathrm{G}$ level ${ }^{10}$ They attributed the strong acidity of the anti form (Meldrum's acid has a bis (anti) form) to greater dipole-dipole electrostatic repulsion interaction between the ether and carbonyl oxygen atoms in the anti conformation. which is significantly relieved in the corresponding enolate anion

The Hammett $\left(\rho_{\mathrm{X}}=-0.15 \sim-0.33\right)$ and Brönsted coefficients $\left(\beta_{\mathrm{X}}=0.15-0.32\right)$ in Table 1 are similar to those obtained in the corresponding reactions with primary amines in aqueous solution $\left(\rho_{\mathrm{X}}=-0.22\right)$. $^{\text {s. }_{0}}$ The $\beta_{\mathrm{X}}$ values are greater than that obtained with secondary amines $\left(\beta_{\mathrm{X}}=0.07^{\text {5a }}\right.$ by two points correlation using piperidine and morpholine) in aqueous solution. but are rather smaller still than those for other benzylamine addition reactions. ${ }^{3}$ (although the $\beta_{\mathrm{X}}$ values are not listed in Table 2, they are numerically quite similar to the $\rho_{\mathrm{X}}$ values in Table 2 due to the near unity slope in the correlation between the $\mathrm{p} K_{\mathrm{a}}$ 's of benzylamine and Hamumett substituent constants. $\sigma$ : i.e., $\delta \mathrm{p} K_{\mathrm{a}} / \dot{\delta} \sigma \cong 1.06$ for benzylamines. ${ }^{11}$ ) The larger $\beta$. value with primary amines than with secondary and tertiary amines seems to represent a common pattern. albeit there are some exceptions. ${ }^{{ }^{5}}$ For example. Skoog and Jencks ${ }^{12}$ reported $\beta_{\mathrm{X}}=0.19$ and 0.17 for the reactions of primary amines and pyridines with phosphorylated 3-methoxypyridine and $\beta_{\mathrm{N}}=0.28$ and 0.22 for the corresponding reactions with phosphorylated 4morpholinopyridine. respectively. The aminolysis of isoquinoline $N$-phosphonate with primary amines and piperidine-morpholine pair gave $\beta \mathrm{x}=0.15$ and 0.0 . respectively. ${ }^{13}$ For the aminoly'sis of $S$-(2.4-dinitrophenyl) $O$-ethyl carbonate. EtOC $(=0)$ SDNP. $\beta_{\mathrm{X}}=0.56^{14}$ and $0.48^{15}$ are obtained with secondary alicyclic amines and quinuclidines. respectively. The $\rho_{\mathrm{Y}}$ values are also small so that charge transfer from the benzylamine nucleophiles to the vinylic carbon in the TS may be small.

On the other hand the cross-interaction constant. $\rho_{\mathrm{XY}}$ $(=-0.33)$. is negative as in other bond forming processes ${ }^{6}$ and the magnitude is similar to those for other relatively faster addition reactions with stronger activating groups. entries 2 (BMN: $\rho_{\mathrm{XY}}=-0.31$ ) and 3 (BID: $\rho_{\mathrm{XY}}=-0.33$ ) in Table 2. The modest size of the $\rho_{\mathrm{YY}}$ value despite the relatively early TS with a lower degree of bond making (lower $\beta_{\mathrm{X}}$ values) may point to a possibility of intramolecular hydrogen bonding ${ }^{16}$ to an oxygen of the $(\mathrm{COO})_{2-}$ $\mathrm{C}\left(\mathrm{CH}_{3}\right)=$ moiety. 6 . or to the central carbon atom. 7. since in these types of hydrogen bonded TS structures the interaction

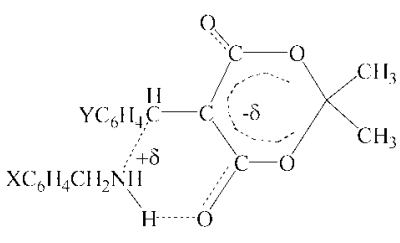

6

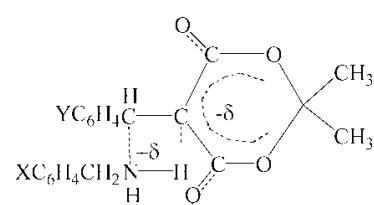

7 between $X$ and $Y$ can be through two routes so that the intensity of interaction. i.e. the magnitude of $\rho_{X Y}$. can have a modest value even though the C-N bond making is small. ${ }^{16}$ Normally the amine nucleophiles approach toward an end carbon of the vinylic double bond from almost directly above (or below) the carbon so that distancewise the $\mathrm{H} \cdots \mathrm{C}$ in 7 may be nearer than $\mathrm{H} \cdots \mathrm{O}$ in 6 .

The kinetic isotope effects involving deuterated benzylamine nucleophiles $\left(\mathrm{XC}_{6} \mathrm{H}_{4} \mathrm{CH}_{2} \mathrm{ND}_{2}\right)$ in Table 3 are all greater than unity $\left(k_{\mathrm{H}} / k_{\mathrm{D}}=1.5-1.7\right)$ and indeed supports such hydrogen bonded TS structure. 6 and 7 . The size of $k_{\mathrm{H}} / k_{\mathrm{D}}$ increases with a stronger electron acceptor substituent in the substrate $(\mathrm{Y})$ as well as in the nucleophile $(\mathrm{X})$ which is in accord with a greater degree of bond making in the TS with electron accepter $\mathrm{Y}$ (with a greater $\beta_{\mathrm{X}}$ value) and the enhanced acidity of the $\mathrm{NH}$ proton with an electron-acceptor substituent $\mathrm{X}$ in the nucleophile. The overall size of the $k_{\mathrm{H}} / k_{\mathrm{D}}$ values ranging 1.5-1.7 are. however. smaller than those of the corresponding values for the substrates with weaker electron acceptor $Z . Z^{\prime}$ exhibiting slower addition rates. e.g. for entries 4,5 , and 6 in Table 2 the $k_{\mathrm{H}} / k_{\mathrm{D}}$ values are larger ranging 2.2-3.1. ${ }^{\text {3ad }}$ This is in line with the greater degree of bond formation in the TS for those substrates (entries 4-6) with larger magnitude of the cross-interaction constants. $\rho_{\mathrm{XY}}$

Table 3. Kinetic isotope effects on the second-order rate constants for the addition of deuterated $\mathrm{X}$-benzylamines $\left(\mathrm{XC}_{0} \mathrm{H}_{4} \mathrm{CH}_{2} \mathrm{ND}_{2}\right)$ to Y-benzylidene Meldrum's acids in acetonitrile at $20.0^{\circ} \mathrm{C}$

\begin{tabular}{ccccc}
\hline $\mathrm{X}$ & $\mathrm{Y}$ & $k_{\mathrm{H}} / \mathrm{M}^{-1} \mathrm{~s}^{-1}$ & $k_{\mathrm{I}} / \mathrm{M}^{-1} \mathrm{~s}^{-1}$ & $k_{\mathrm{H}} / k_{\mathrm{I}}$ \\
\hline$p$-OMe & $p-\mathrm{OMe}$ & $74.4( \pm 0.1)$ & $51.3( \pm 0.5)$ & $1.45 \pm 0.02^{\circ}$ \\
$p$-OMe & $p-\mathrm{Me}$ & $86.4( \pm 0.9)$ & $57.6( \pm 0.5)$ & $1.50 \pm 0.02$ \\
$p$-OMe & $\mathrm{H}$ & $101( \pm 1)$ & $64.7( \pm 0.8)$ & $1.56 \pm 0.03$ \\
$p-\mathrm{OMe}$ & $p-\mathrm{Cl}$ & $132( \pm 2)$ & $81.5( \pm 0.9)$ & $1.62 \pm 0.03$ \\
$p-\mathrm{Cl}$ & $p-\mathrm{OMe}$ & $62.6( \pm 0.8)$ & $40.9( \pm 0.4)$ & $1.53 \pm 0.03$ \\
$p-\mathrm{Cl}$ & $p-\mathrm{Me}$ & $68.0( \pm 0.9)$ & $42.8( \pm 0.4)$ & $1.59 \pm 0.03$ \\
$p-\mathrm{Cl}$ & $\mathrm{H}$ & $76.6( \pm 0.9)$ & $45.6( \pm 0.4)$ & $1.68 \pm 0.02$ \\
$p-\mathrm{Cl}$ & $p-\mathrm{Cl}$ & $91.0( \pm 0.1)$ & $52.3( \pm 0.5)$ & $1.74 \pm 0.02$ \\
\hline
\end{tabular}

Standard deviations.

Table 4. Activation parameters for the addition of X-benzy!amines to Y-benzylidene Meldrum's acids in acetonitrile

\begin{tabular}{cccc}
\hline $\mathrm{X}$ & $\mathrm{Y}$ & $\Delta H^{-} / \mathrm{kcal} \mathrm{mol}^{-1}$ & $-\Delta S^{-} / \mathrm{cal} \mathrm{mol}^{-1} \mathrm{~K}^{-1}$ \\
\hline$p$-OMe & $p-\mathrm{OMe}$ & 3.9 & 37 \\
$p$-OMe & $p-\mathrm{Cl}$ & 4.1 & 36 \\
$p-\mathrm{Cl}$ & $p-\mathrm{Me}$ & 3.8 & 38 \\
$p$-Cl & $p-\mathrm{Cl}$ & 3.8 & 37 \\
\hline
\end{tabular}

"Calculated by the Eyring equation. The maximum errors calculated (by the method of Wiberg. K. B. ref. 17) are $=0.5 \mathrm{kcal} \mathrm{mol}^{-1}$ and $=2$ e.u. for $\Delta H^{-}$and $\Delta S^{\dagger}$, respectively: 
As expected from a hydrogen bonded cyclic TS the enthalpies of activation are low. $\Delta H^{\ddagger} \cong 4 \mathrm{kcal} \mathrm{mol}^{-1}$. and the entropies of activation are large negative $\Delta S^{\ddagger} \cong-37$ e.u. (Table 4). The addition step is facilitated by the simultaneous hydrogen bonding (low $\Delta H^{*}$ ) but the TS is constrained (large negative $\Delta S^{\dagger}$ ) in a cyclic structure.

\section{Conclusion}

The reactions of benzylamine additions to benzylidene Meldnum's acids (BMA) are unusually fast in acetonitrile. which can be ascribed to the abnormally high acidity of the Meldnum's acid. The reactions proceed by simultaneous addition of amine and proton to the vinylic double bond with hydrogen bonded cyclic transition state. Relatively low $\beta_{\mathrm{x}}$. $\rho_{\mathrm{X}}$ and $\rho_{\mathrm{Y}}$ values are interpreted to indicate an early transition state. The normal kinetic isotope effects $\left(k_{\mathrm{H}} / k_{\mathrm{D}}=1.5\right.$ 1.7) involving deuterated benzylamine necleophiles. a modest size of the negative cross-interaction constant. $\rho_{\mathrm{XY}}=$ -0.33 . and activation parameters support the proposed mechanism

\section{Experimental Section}

Materials. Merck GR acetonitrile was used after three distillations. The benzylamine nucleophiles. Aldrich GR. were used after recrystallization. Toluene. Meldnum's acid and piperidine were Aldrich reagents.

Preparation of Benzylidene Meldrum's Acids. The benzylidene Meldrum's acids were prepared by the literature method of Schuster $e t$ al $^{18}$ A solution of Meldnun's acid (3 mmol) and benzaldehyde $(3 \mathrm{mmol})$ in toluene was treated with a few drops of piperidine and refluxed for $3 \mathrm{~h}$. The solution was cooled. some of the toluene was evaporated. and the dark-colored solid was removed by filtration to obtain $(85 \%)$ crude material. This was recrystallized from toluene. Melting points. IR and ${ }^{1} \mathrm{H}$ and ${ }^{13} \mathrm{C}$ NMR $(400 \mathrm{MHz})$ data were found to agree well with the literature values. ${ }^{1 \S}$

Kinetic Measurements. The reaction was followed spectrophotometrically by monitoring the decrease in the concentration of benzylidene Meldrum's acids. [BMA]. at $\lambda_{\text {max }}$ of the substrate to over $80 \%$ completion. The reaction was studied under pseudo-first-order condition. [BMA] $\cong 6.0 \times 10^{-5} \mathrm{M}$ and $[\mathrm{BnA}]=\sim 10^{-3} \mathrm{M}$ at $20.0 \pm 0.1^{\circ} \mathrm{C}$. The psendo first-order rate constant. $k_{\mathrm{obs} d}$. was determined from the slope of the plot $(r>0.993)$ of $\ln [\mathrm{BMA}] v$ time. Second-order rate constants. $k$. were obtained from the slope of a plot $(r>0.995)$ of $k_{0 b s d}$ w $[\mathrm{BnA}]$ with more than five concentrations of benzy lamine and were reproducible to within $\pm 3 \%$.

Product Analysis. The analysis of final products was difficult due to partial decomposition during product separation and purification. We therefore analyzed the addition reaction of $p-\mathrm{MeOC}_{6} \mathrm{H}_{4} \mathrm{CH}_{2} \mathrm{NH}_{2}$ to $p-\mathrm{ClC}_{6} \mathrm{H}_{4} \mathrm{CH}=\mathrm{C}(\mathrm{COO})_{2} \mathrm{C}_{2}\left(\mathrm{CH}_{3}\right)_{2}$ by ${ }^{~}{ }^{3} \mathrm{C} \mathrm{NMR}(400 \mathrm{MHz})$ at appropriate intervals under exactly' the same reaction conditions as the kinetic measurement in $\mathrm{CD}_{3} \mathrm{CN}$ at $30.0^{\circ} \mathrm{C}$. Initially we found a peak for $\mathrm{CH}$ in the reactant. $p-\mathrm{ClC}_{6} \mathrm{H}_{4} \mathrm{CH}=\mathrm{C}(\mathrm{COO})_{2} \mathrm{C}\left(\mathrm{CH}_{3}\right)_{2}$. at 7.62 ppm. which was gradually reduced and two new peaks for $\mathrm{CH}-\mathrm{CH}$ in the product. $p$ - $\mathrm{ClC}_{6} \mathrm{H}_{4}\left(p-\mathrm{MeOC}_{6} \mathrm{H}_{4} \mathrm{CH}_{2} \mathrm{NH}\right) \mathrm{CH}-\mathrm{CH}(\mathrm{COO})_{2-}$ $\mathrm{C}\left(\mathrm{CH}_{3}\right)_{2}$. grew at 3.93 and $4.69 \mathrm{ppm}$ as the reaction proceeded. No other peaks or complications were found during the reaction except the 3 peak height changes indicating that the reaction proceeds with no other side reactions.

Acknowledgment. This work was supported by Korea Research Foundation Grant (KRF-2002-070-C00061).

\section{References}

1. (a) Patai. S.: Rappoport, Z. In The Chentisn of Alkenes. Patai, S. Ed.: Interscience: New York. 1964: p 469. (b) Bernasconi. C. F. Tetrahedron 1989. 45.4017. (c) Rappoport. Z.: Ladkani. D. Chem. Scr. 1974. 5. 124. (d) Rappoport. Z. Adv. Phus. Org. Chem. 1969. 7. 1. (e) Modena, G. Acc. Chent Res. 1971, 4. 73. (1) Miller, S. I. Tetrahedhon 1977. 33. 1211. (g) Rappoport Z. Acc. Chent Res. 1981. 14, 7. (h) Rappoport. Z. Ace. Chem. Res 1992, 25. 474. (i) Bernasconi. C. F. Acc. Chem. Res. 1987. 20. 301.

2. Schreiber. B.: Martinek. H.: Wolscham. P.: Schuster. P. $d$. Am Chem. Soc. 1979.101.4708.

3. (a) Oh. H. K.: Yang. J. H.: Sung. D. D.: Lee, I. J. Chen. Soc. Perkin Trans. 2 2000. lol. (b) Oh, H. K; Yang. J. H.; Lee. H. W. Lee. I. J. Org. Chem. 2000, 65. 2188. (c) Oh. H. K.: Yang, J. H. Lee. H. W. Lee. I. J. Org. Chem. 2000. 65.5391. (d) Oh. H. K.: Kim. T. S.: Lee. H. W.: Lee. I. J. Chem. Soc. Perhin Trans. 2 2002. 282 .

4. (a) Arnett. E. M.: Harrelson. . . A. Tr. $J$. Am. Chem Soc. 1987. 109. 809. (b) Wang, X; Houk, K. N. J. Am. Chent Soc. 1988. 110. 1870. (c) Wiberg, K. B.: Laidig. K. E. J. Am. Chem. Soc. 1988. 110. 1872

5. (a) Bernasconi. C. F.: Fornarini. S. J. Am Chem Soc. 1980. 102. 5329. (b) Bernasconi. C. F.: Leonarduzzi. G. D. J. Am. Chem. Soc. 1982. 104. 5133. (c) Bernasconi. C. F.: Murray. C. J. J.Am. Chem. Soc. 1986, 108, 5251. (d) Bernasconi, C. F.: Panda, N. J. Org. Chent 1987, 52. 3042. (e) Bernasconi. C. F.: Ketner. R. J. J. Org. Chent $1998,63,6266$.

6. (a) Lee. I. Adv Phus. Ong Chem 1992. 27.57 (b) Lee. I.: Lee. H. W. Collect. Czech. Chem. Conmun. 1999. 64. 1529. (c) Lee. I. Chem. Soc, Ren 1990. 19.317.

7. Hansch. C.: Leo, A.: Taft, R. W. Chem. Rev: 1991. 91. 165.

8. Blackwell. L. F.: Fischer. A; Miller. I. J.: Topsom. R. D.: Vaughan, J. J. Chem. Soc. $1964,3588$.

9. Oh. H. K.: Lee. T. Y.: Lee. I. Bull Rorea Chem. Soc 1998. 19. 1198.

10. (a) Hehre. W. I.: Radom. L.: Schleyer. P. v. R.: Pople. J. A. At Intio Molcutar Orbital Theon: Wiley: New York, 1986; Chapter 4. (b) Foresman, J. B.; Frisch. .E. Exploring Chentistry with Electronic Sthuctue Methods, 2nd Ed: Gaussian Ine.: Pittsburgh. 1996: Part 2

11. Page. M: Williams. A. Organic and Bio-organic Mechanisms: Longmant: Harlow: 1997: p 259.

12. Skoog. M. T; Jencks, W. P. J. An. Chem. Soc. 1984. 106.7597.

13. Bourne. N.; Williams, A. J. Am. Chent Soc. 1984, 106.7591.

14. Castro. E. A.; Ibanez, F.: Salas, M.: Santos, J. G. J. Org Chent. 1991. 56. 4819 .

15. Castro. E. A.: Munoz. P.: Santos. T. G. J. Org. Chem. 1999. 64. 8298.

16. Lee. I. Chent Soc. Rev: $1995,24,223$.

17. Wiberg. K. B. Phwsical Orgmic Chentism: Wiley: New York. 1964: 378

18. Schuster. P.: Polansky. O. E.: Wessely. F. Monatsh Chem 1963. 95.53. 